\title{
miR-139 and miR-200c regulate pancreatic cancer endothelial cell migration and angiogenesis
}

\author{
LEI LI ${ }^{1}$, BAIWEN LI ${ }^{1}$, DAFAN CHEN ${ }^{1}$, LIYAN LIU ${ }^{1}$, CHEN HUANG $^{2}$, \\ ZHANJUN LU ${ }^{1}$, LUNGEN LUN ${ }^{1}$ and XINJIAN WAN ${ }^{1}$ \\ Departments of ${ }^{1}$ Gastroenterology and ${ }^{2}$ General Surgery, Shanghai First People's Hospital, \\ School of Medicine, Shanghai Jiaotong University, Shanghai 201620, P.R. China
}

Received November 27, 2014; Accepted January 20, 2015

DOI: $10.3892 /$ or.2015.3945

\begin{abstract}
Pancreatic cancer remains the fourth deathliest cancer worldwide with a 5-year survival rate of only $4 \%$. The present study tested the hypothesis that dysregulated microRNA (miRNA) expression by pancreatic cancer endothelial cells (CECs) may regulate angiogenesis. Primary EC cultures were established from the pancreatic tumor and adjacent normal tissues of three pancreatic cancer patients. A miRNA microarray was used to identify miRNAs that were differentially expressed. The expression patterns of four highly expressed miRNAs in CECs were confirmed by qPCR analysis. The effects of dysregulated miRNA expression on CEC proliferation, migration and tube formation were determined after transfection with specific miRNA inhibitors. The expression of 14 miRNAs was increased by $>20$-fold in the the CECs of all three pancreatic patients; the increased expression of miR-200c and miR-139 in CECs was confirmed. miR-1, mir-139 and miR-200c inhibitors significantly reduced CEC migration (all $\mathrm{P}<0.05$ ), yet not proliferation. The average tube length and total loop number were also significantly decreased upon miR-139 and miR-200c inhibition in all three CEC cultures (all $\mathrm{P}<0.05$ ). Upregulation of $\mathrm{miR}-139$ and $\mathrm{miR}-200 \mathrm{c}$ expression may increase CEC migration and tube formation, which suggests that these miRNAs may regulate pancreatic tumor angiogenesis.
\end{abstract}

\section{Introduction}

Despite treatment advances in other types of cancer, pancreatic cancer remains the fourth deathliest cancer worldwide with a 5 -year survival rate of only $4 \%$ (1) in part since it is rarely detected at an early stage. For patients with inoperable locally advanced pancreatic cancer, standard treatment with chemo-

Correspondence to: Dr Xinjian Wan, Department of Gastroenterology, Shanghai First People's Hospital, School of Medicine, Shanghai Jiaotong University, Shanghai 201620, P.R. China E-mail: wanxj99@163.com

Key words: angiogenesis, biomarker, endothelial cell, microRNA, migration, pancreatic cancer therapy or chemoradiotherapy results in a median survival time of 6-9 months (2) with combined radiochemotherapy resulting in improved 6-, 12- and 18-month survival rates (3). Therefore, current efforts have focused on identifying novel therapeutic targets for the treatment of pancreatic cancer.

Angiogenesis is crucial for the growth and progression of tumors. In isolated perfused thyroid glands, transplanted melanoma cells grew into tumors of only 1-2 mm in diameter and were not vascularized, suggesting that neovascularization is required for tumor growth (4). Tumors may become necrotic or even apoptotic in the absence of vascular support $(5,6)$; therefore, angiogenesis inhibition has become an important therapeutic strategy in the prevention of tumor expansion and metastasis (7). Evidence suggests that specific microRNAs (miRNAs) can regulate angiogenesis through the downregulation of angiogensis-related genes by interacting with their 3' untranslated region (UTR) (8). Recent studies that disrupted the function of Dicer and Drosha have revealed the important roles of certain miRNAs, known as angiomiRs, in regulating angiogenesis and modulating endothelial cells (ECs) (9-11). Dicer hypomorphic mouse lines have defects in vascular remodeling during development and ovarian angiogenesis $(9,10)$. In addition, in vitro knockdown of Dicer or Drosha in human ECs decreased angiogenesis (11).

AngiomiRs regulate angiogenesis either cell-autonomously or non-cell-autonomously (12). miR-296 targets hepatocyte growth factor-regulated tyrosine kinase substrate mRNA, thereby suppressing the degradation of vascular endothelial growth factor receptor 2 (VEGFR2) and platelet-derived growth factor receptor- $\beta$ (PDGFR- $\beta$ ) (13). In addition, miR-296 inhibition decreased tumor xenograft angiogenesis in vivo (13). Conversely, ectopic expression of miR-18a inhibited gastric cancer cell xenograft growth in vivo by reducing tumor angiogenesis (14). miRNAs also modulate the angiogenic properties of human umbilical vein ECs (HUVECs) (15); suppression of miR200a expression inhibited HUVEC viability and migration (16). Ectopic expression of miR-199a suppressed EC migration and reduced the expression of vascular cell adhesion molecule-1 (VCAM-1) and intracellular adhesion molecule-1 (ICAM-1) (17). miR-149 regulated fibroblast growth factor 2 (FGF2)-induced EC proliferation and migration (18).

Given the importance of angiogenesis in tumor progression, the present study was undertaken to test the hypothesis that 
certain miRNAs expressed in cancer-associated ECs (CECs) may regulate angiogenesis. We identified miRNAs that were differentially expressed in primary EC cultures derived from three pancreatic cancer tissues as compared to those from adjacent normal tissues. Inhibition of miR-139 or miR-200c significantly reduced cancer endothelial cell (CEC) migration, the average tube length, and total loop number, suggesting that they play a role in tumor angiogenesis.

\section{Materials and methods}

Patient tissue samples. Pancreatic tumor and normal adjacent tissues were obtained from three pancreatic cancer patients who underwent surgery in the Department of General Surgery, Shanghai First People's Hospital, Shanghai Jiaotong University from October 2012 to May 2013. According to the tumornode-metastasis (TNM) staging system (7th edition) of the American Joint Commission on Cancer (AJCC), all patients had stage I or II (T1-3, N0-1, M0) pancreatic cancer. None of the patients had received chemotherapy or cytotoxic agents within the last 12 months prior to the inclusion into this study. None of the patients showed clinical signs for active infectious diseases. Patients with stage III and IV pancreatic cancer with locally advanced unresectable foci (T4) and/or systemic metastases (M1) were excluded. Informed consent was obtained from all study participants. The present study was approved by the Ethics Committee of Shanghai First People's Hospital, Shanghai Jiaotong University, Shanghai, China.

Establishment of primary endothelial cell cultures from human pancreatic tumor samples. Primary endothelial cell cultures derived from human pancreatic tumor masses or adjacent normal tissue were prepared according to the method reported by Naschberger et al (19). Briefly, after tissues were cut into $1-\mathrm{mm}^{3}$ blocks, they were digested with collagenase II $(17,100 \mathrm{U} / \mathrm{g})$ in $5 \mathrm{ml}$ of endothelial basal medium (EBM-2) supplemented with $0.5 \%$ fetal bovine serum (FBS) (EBM-low; both from Lonza, Cologne, Germany) at $37^{\circ} \mathrm{C}$ with $5 \% \mathrm{CO}_{2}$ for $1 \mathrm{~h}$ under constant agitation. Following digestion, cells were filtered (cell strainer $100 \mu \mathrm{m}$; BD Biosciences, Franklin Lakes, $\mathrm{NJ}$, USA) and isolated by centrifugation at $500 \mathrm{xg}$ for $5 \mathrm{~min}$ at $20^{\circ} \mathrm{C}$. The cell pellet was resuspended in $5 \mathrm{ml}$ of EGM-2-MV (EGM-2-MV BulletKit; Lonza), and the cell suspension was added to flasks pre-coated with $1.5 \%$ gelatin. The growth medium was refreshed every 2 days for 5-7 days until the cell confluence reached $70-80 \%$. After the cells were detached with 1-2 ml of Accutase (Life Technologies, Carlsbad, CA, USA), they were washed with EGM-2-MV. The cells were resuspended in $60 \mu \mathrm{l}$ of MACS buffer (1X PBS pH 7.2, $0.5 \%$ bovine serum albumin, $2 \mathrm{mM}$ EDTA), and then were incubated with $20 \mu 1$ of CD31 beads (CD31 MicroBead kit; Miltenyi Biotec, Bergisch Gladbach, Germany) at $4^{\circ} \mathrm{C}$ for $15 \mathrm{~min}$. After washing with MACS buffer, the cells were resuspended in $1 \mathrm{ml}$ MACS buffer, which was applied to a MACS separation column (Miltenyi Biotec), and the endothelial cells were isolated following the manufacturer's instructions. The cell concentration was adjusted to $1-2 \times 10^{4} / \mathrm{cm}^{2}$ and cultured on $25 \mathrm{~T}$ flasks pre-coated with $0.5 \%$ gelatin. Cells were cultured until complete confluency was reached, and the medium was refreshed every 2 days.
miRNA extraction. Total RNA was isolated using the mirVana $^{\mathrm{TM}}$ microRNA isolation kit according to the manufacturer's instructions (Ambion, Austin, TX, USA). In brief, the sample was first lysed in a denaturing lysis solution, and the lysate was then subjected to phenol-chloroform extraction. After purification over a glass-fiber filter, the total RNA integrity was confirmed with an Agilent 2100 Bioanalyzer (Agilent Technologies, Palo Alto, CA, USA).

miRNA microarray and data analysis. The miRNA expression profiles in CECs were compared with those of normal endothelial cells (NECs) derived from the same patient. Affymetrix FlashTag ${ }^{\circledR}$ Biotin HSR was used for miRNA labeling and hybridization onto the Affymetrix GeneChip ${ }^{\circledR}$ MicroRNA 3.0 Array (both from Affymetrix, Santa Clara, CA, USA) following the manufacturer's instructions. The miRNA expression profile was scanned through a GeneChip ${ }^{\circledR}$ Scanner 3000 (cat. \#00-00212, Affymetrix), and primary data were analyzed using GeneChip-compatible ${ }^{\mathrm{TM}}$, Command Console Software 3.1 and Expression Console Software. The CEC and NEC miRNA expression profiles of the same patient were compared to identify differentially expressed mRNAs. In addition, the array results were also compared against the miRNA databases, microrna.org and TargetScan, to identify candidate miRNAs that are relevant to angiogenesis.

Candidate miRNA validation. The differential expression of miR-200c, miR-182, miR-139-5p and miR-200b was validated by qPCR analysis using the stem-loop TaqMan MicroRNA Assay (Applied Biosystems, Foster City, CA, USA), according to the manufacturer's instructions. Briefly, mature candidate miRNAs were reverse transcribed into cDNA from $10 \mathrm{ng}$ of total RNA with mature miRNA-specific looped RT primers from the TaqMan MicroRNA assays kit and reagents from the TaqMan MicroRNA Reverse Transcription kit (Applied Biosystems) following the manufacturer's instructions. Real-time PCR was performed on the 5'-extended cDNA with Applied Biosystems TaqMan 2X Universal PCR Master Mix and the appropriate 5X TaqMan MicroRNA Assay Mix (both from Applied Biosystems) for each miRNA of interest. For each sample, the threshold cycle $(\mathrm{Ct})$ was calculated by the ABI 7500 Sequence Detection System software. Standard curves were used to determine miRNA concentration in the samples, which were then normalized to small nuclear RNA U (RNU) RNA.

miRNA knockdown in CECs. The specific inhibitors for miR-139 or miR-200c (MiScript microRNA Inhibitor; Qiagen, Hilden, Germany) were added into CEC cultures to evaluate the effect of these miRNAs on CEC proliferation. In addition, since miR-1 regulates angiogenesis (i.e., enhanced tube formation and migration of human-derived cardiomyocyte progenitor cells) (20), a miR-1 inhibitor (Qiagen) was used as a positive control. An inhibitor with scrambled sequence that has no homology to any known mammalian gene (Qiagen) was used as a negative control. Briefly, cells were seeded in a 24-well plate at a density of $0.4-1.6 \times 10^{5}$ cells/well in $500 \mu \mathrm{l}$ of culture medium containing serum and antibiotics. After $4 \mathrm{~h}$, cells were incubated with $50 \mathrm{nM}$ miRNA inhibitor diluted in $50 \mu \mathrm{l}$ of culture medium without serum and with $1.5 \mu \mathrm{l}$ 
Table I. Differentially expressed miRNAs with a >20-fold increased expression in CECs relative to NECs $(\mathrm{N}=3)$.

\begin{tabular}{lc}
\hline miRNA & $\begin{array}{c}\text { Fold-change in expression } \\
(\text { CEC/NEC })^{\mathrm{a}}\end{array}$ \\
\hline hsa-miR-25* & $63.47 \pm 17.96$ \\
hsa-miR-27a* & $86.33 \pm 32.15$ \\
hsa-miR-92a-1* & $62.63 \pm 22.31$ \\
hsa-miR-139-5p & $356.53 \pm 181.85$ \\
hsa-miR-182 & $951.97 \pm 86.51$ \\
hsa-miR-183 & $99.9 \pm 57.27$ \\
hsa-miR-192 & $47.77 \pm 20.83$ \\
hsa-miR-194 & $55.2 \pm 15.14$ \\
hsa-miR-200a & $46 \pm 15.83$ \\
hsa-miR-200b* & $93 \pm 39.66$ \\
hsa-miR-200b & $151.07 \pm 67.69$ \\
hsa-miR-200c & $4,574.97 \pm 2,209.62$ \\
hsa-miR-203 & $77.87 \pm 37.57$ \\
hsa-miR-375 & $58.2 \pm 33.34$ \\
\hline
\end{tabular}

a Mean \pm SD miRNA expression in three pancreatic cancer patients. CECs, cancer endothelial cells; NECs, normal endothelial cells.

HiPerfect transfection reagent (Qiagen). The cells were incubated with the transfection complexes under normal growth conditions, and gene expression was monitored after $12 \mathrm{~h}$ by qPCR. qRT-PCR data were calculated as $2^{-\Delta \Delta \mathrm{Ct}}$ after normalizing to the control.

Cell proliferation assay. Cell proliferation was assessed using the MTT assay (Sigma, St. Louis, MO, USA) $48 \mathrm{~h}$ after siRNA inhibition following the manufacturer's instructions.

Cell migration assay. Transwell migration assay were conducted $48 \mathrm{~h}$ after siRNA inhibition using a fluorometric cell migration assay kit with polycarbonate membrane inserts $(5-\mu \mathrm{m}$ pore size; Cell Biolabs, San Diego, CA, USA) using a modified protocol described by Chim et al (21). Briefly, cells were serum-starved overnight in Dulbecco's modified Eagle's medium (DMEM) prior to initiation of the experiment. The lower chambers were filled with $1 \mathrm{ml}$ of medium containing $10 \%$ serum. Cells $\left(4 \times 10^{4}\right)$ were resuspended in $200 \mu \mathrm{l}$ of Opti-MEM and added to the upper chamber. After $24 \mathrm{~h}$ at $37^{\circ} \mathrm{C}$, migrating cells were counted after staining with crystal violet.

Tube formation assay. After cells were serum-starved overnight in DMEM, they were seeded in 24-well plates that were coated with Geltrex ${ }^{\mathrm{TM}}$ reduced growth factor basement membrane matrix (Invitrogen, Carlsbad, CA, USA) and incubated at $37^{\circ} \mathrm{C}$ for $30 \mathrm{~min}$ with Opti-MEM. Medium was then removed and replaced with the medium containing $10 \%$ serum and incubated at $37^{\circ} \mathrm{C}$ for $24 \mathrm{~h}$. Four randomly selected fields of view were analyzed, and tube formation was quantified by measuring the length of tube-like structures and the number of branching points. Tube length was assessed by drawing lines along the tube-like structure and measuring the length

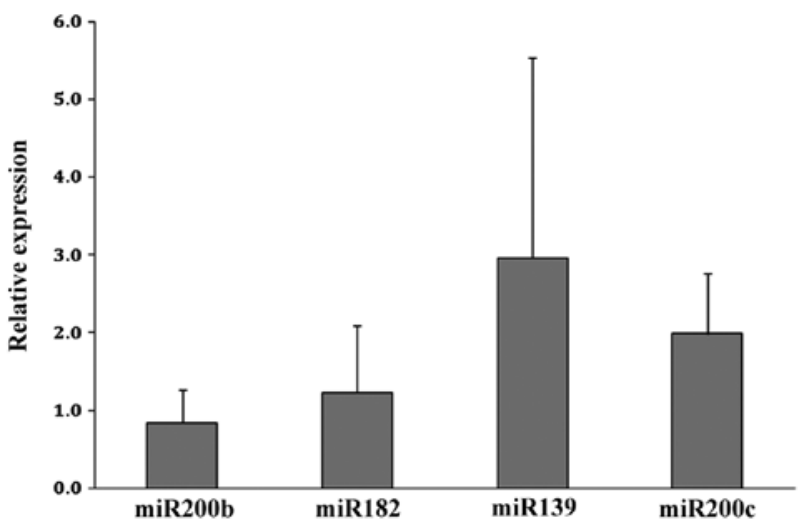

Figure 1. Validation of increased miR-139 and miR-200c expression in CECs relative to NECs. miRNA levels in three pancreatic cancer patients were determined by qPCR. Data are presented as mean $\pm \mathrm{SD}$ of the relative miRNA expression as calculated by the $2^{-\Delta \Delta \mathrm{Ct}}$ method. CECs, cancer endothelial cells; NECs, normal endothelial cells.

of the line in pixels using a modified protocol as previously described (21).

Statistical analysis. For cell proliferation and migration as well as tube length and total loops, data are presented as mean \pm standard deviation (SD). One-sample t-tests were performed to evaluate the cell proliferation with the mean of the control group set to 1 . Differences among the negative control, miR-1, mir-139 and miR-200c inhibitor groups were also assessed by one-way ANOVA with a post-hoc LSD test as for pair-wise comparisons. One-sample t-tests were also performed to evaluate the mean tube length or total loops set as 1 . Moreover, differences between the negative control and miR-1 inhibitor groups were compared using the two-sample t-test. Statistical assessments were two-tailed, and P-values $<0.05$ were considered to indicate statistically significant results. SPSS 18.0 statistics software (SPSS, Inc., Chicago, IL, USA) was used for all statistical analyses.

\section{Results}

miRNA expression profiles in CECs and NECs. The miRNA expression profiles of CECs were compared with those of the NECs in three pancreatic patients. As shown in Table I, 14 miRNAs were upregulated by $>20$-fold in the CECs as compared to NECs, including hsa-miR-139-5p, hsa-miR-182, hsa-miR-183, hsa-miR-192, hsa-miR-194, hsa-miR-200a, hsa-miR-200b*, hsa-miR-200b, hsa-miR-200c, hsa-miR-203, hsa-miR-25*, hsa-miR-27a*, hsa-miR-375 and hsa-miR-92a-1*.

Validation of differential expression of candidate angiomiRs in CECs and NECs. We compared the primary miRNA data with available miRNA databases (http://www.microrna.org; www.targetscan.org) to identify candidate angiomiRs.

Of the miRNAs with $>20$-fold increased expression, miR-182, miR-183, miR-192, miR-194, the miR-200 family, miR-203, miR-27a*, miR-375 and miR-92a-1* have been implicated in regulating tumor angiogenesis (16,22-32). We chose to validate the upregulated expression of miR-200b, miR-182, miR-139 and miR-200c using qPCR analysis as 

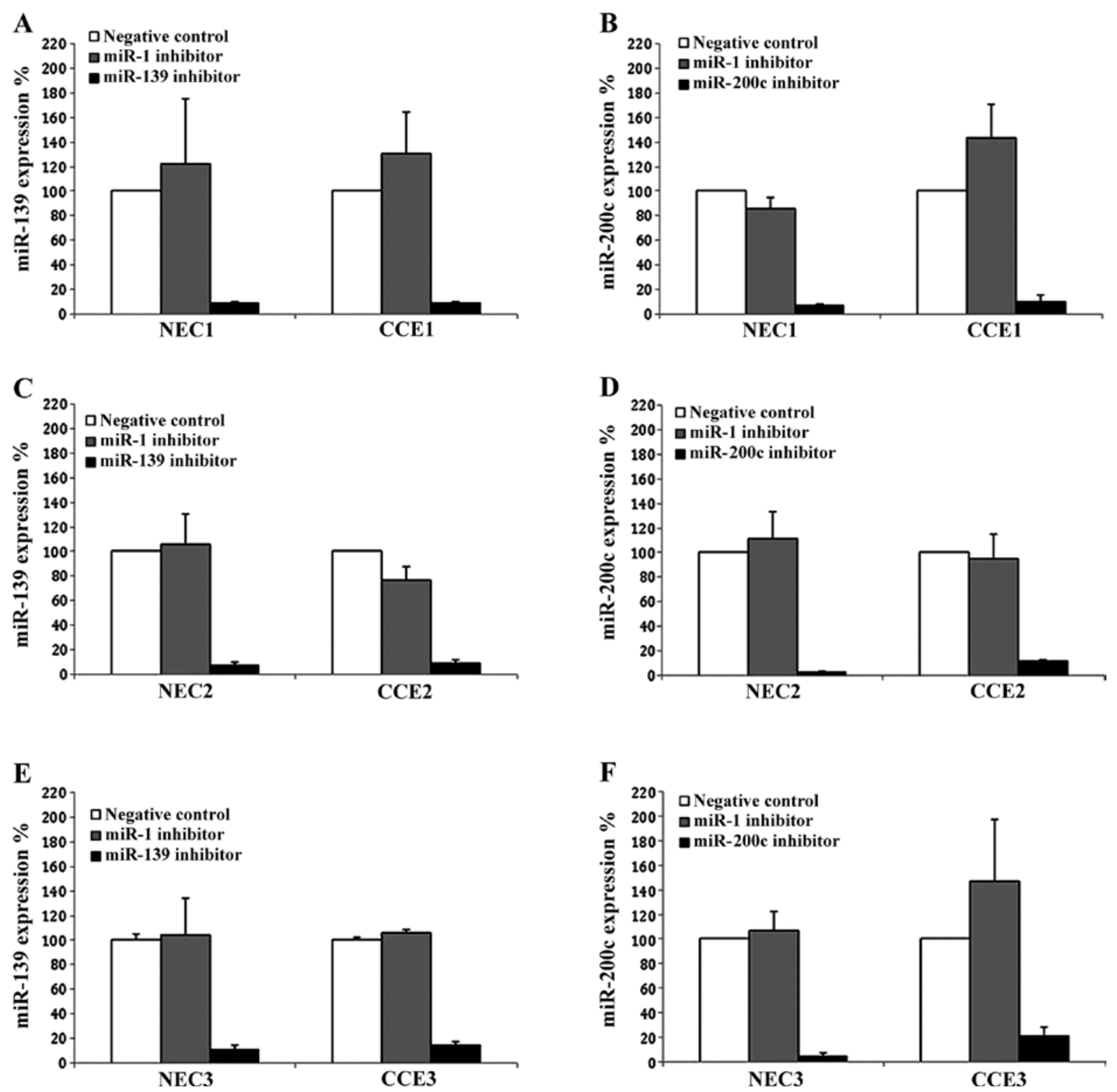

Figure 2. Efficiency of miRNA knockdown. NEC and CEC cultures were obtained from patients $1(\mathrm{~A}$ and B), $2(\mathrm{C}$ and $\mathrm{D})$ and $3(\mathrm{E}$ and F) and were transfected with vector alone or inhibitors of miR-1, miR-139 or miR-220c. The expression of miR-139 (A, C and E) and miR-220c (B, D and F) was determined by qPCR. Data are presented as mean $\pm \mathrm{SD}$ of the relative expression levels for each subject as determined using the $2^{-\Delta \Delta \mathrm{Ct}}$ method. ( $\mathrm{n}=3$ for each pancreatic patient). NEC1-3, normal endothelial cells from patients 1-3; CEC1-3, cancer endothelial cells from patients 1-3.

these candidate angiomiRs had the greatest increase in fold-expression in the CECs (Table I). As shown in Fig. 1, the upregulated expression of miR-139 and miR-200c was confirmed in CECs relative to NECs.

Effect of miRNA on CEC proliferation. To determine whether either miR-139 or miR-200c influences CEC proliferation, specific inhibitors against them were utilized. As shown in Fig. 2, the efficiency of the miRNA inhibition was confirmed in three different pairs of NEC and CEC cultures. Each miRNA inhibitor suppressed the expression of their target miRNA by at least $80 \%$. We next determined whether inhibition of either miR-139 or miR-200c could influence CEC proliferation using MTT assays. As shown in Fig. 3, cell proliferation was not altered upon inhibition of miR-139 or miR-200c as compared to the negative control group. Similar results were obtained after inhibition of miR-1, which is a known regulator of angiogenesis (20). However, cell proliferation was significantly decreased in all groups as compared to the untransfected control cells (all $\mathrm{P}<0.05$ ). These data suggest that neither miR-139 nor miR-200c influences pancreatic CEC proliferation.

Effect of miR-139 and miR-200c on CEC migration. The effects of miR-139 and miR200c on CEC migration were next evaluated using their specific inhibitors. As compared to the untransfected cells, cell migration in all the samples was significantly decreased (all $\mathrm{P}<0.05$, Fig. 4). Notably, significantly reduced CEC migration was observed after transfection with the miR-1, miR-139 and miR-200c inhibitors compared to the negative control group (all $\mathrm{P}<0.05$ ). These data suggest that miR-139 and miR-200c regulate CEC migration. 


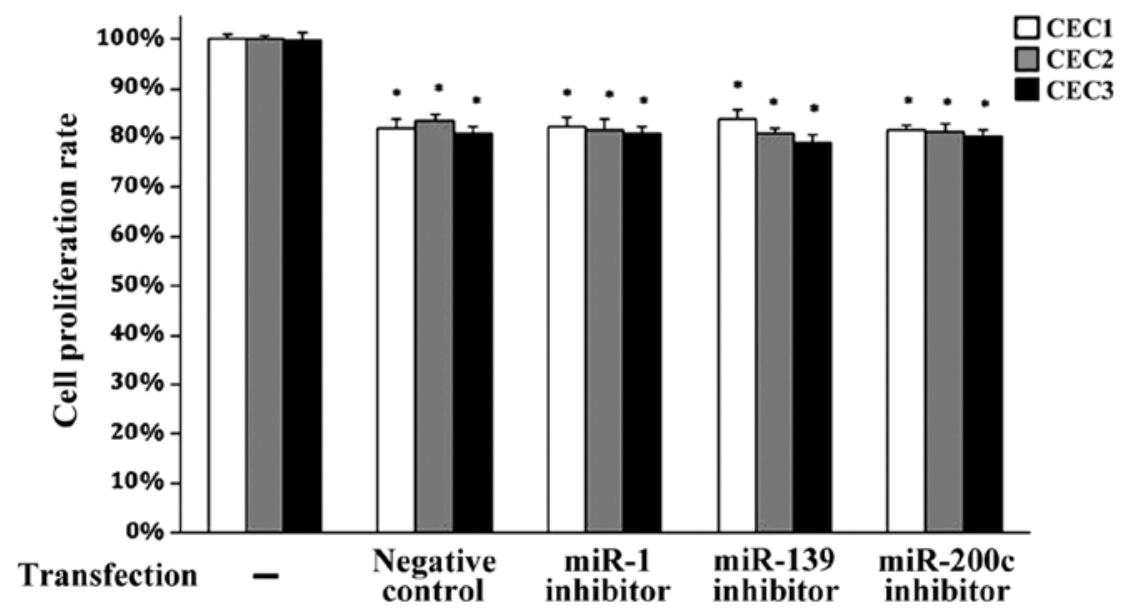

Figure 3. miR-139 and miR-220c do not alter CEC proliferation. CEC proliferation was determined using the MTT assay after transfection with the indicated inhibitors. Data are presented as mean $\pm \mathrm{SD}$ for each condition ( $\mathrm{n}=3 /$ condition). $\mathrm{P}<0.05$, indicates a significant difference as compared to the untransfected controls. CEC1-3, cancer endothelial cells from patients 1-3.

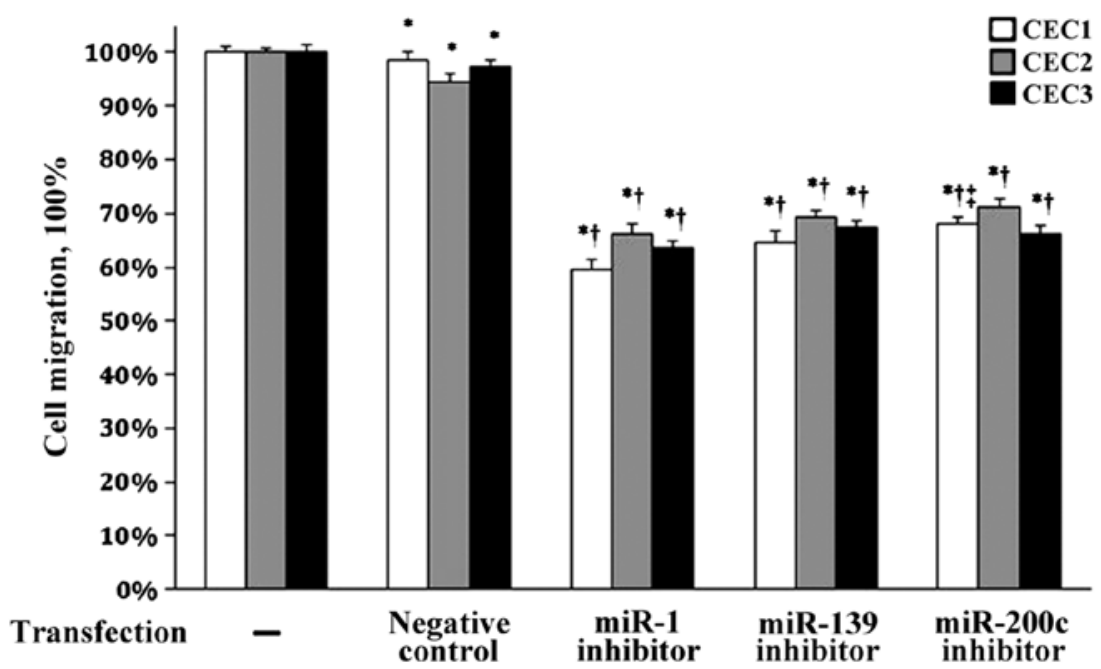

Figure 4. Cell migration was inhibited by miR-139 and miR-220c. After transfection with the indicated inhibitors, CEC migration was determined using Transwell migration assays. Data are presented as mean $\pm \mathrm{SD}$ for each condition ( $\mathrm{n}=3 /$ condition). ${ }^{*} \mathrm{P}<0.05$, indicates a significant difference as compared with the untransfected controls. $\mathrm{f}<0.05$, indicates a significant difference as compared to the "negative control and ${ }^{\star} \mathrm{miR}-1$ inhibitor groups. CEC1-3, cancer endothelial cells from patients 1-3.

Effect of miR-139 and miR-200c on angiogenesis in CECs. The effects of miR-139 and miR200c on CEC tube formation were next evaluated as an in vitro measure of their effects on angiogenesis. Representative images of the cells from all three CEC cultures are shown in Fig. 5A-C. As shown in Fig. 5D and $\mathrm{E}$, the average tube length and total loop number were significantly decreased with miR-139 and miR-200c inhibition in all three CEC cultures compared to those of the negative control group (all $\mathrm{P}<0.05$ ). No such changes were observed with miR-1 inhibition. Thus, miR-139 and miR-200c may regulate vasculature formation during angiogenesis.

\section{Discussion}

Inhibition of angiogenesis to suppress tumor expansion and metastasis in pancreatic cancer has become a promising therapeutic strategy for many types of cancer. Although the importance of miRNAs in vasculogenesis was illustrated in Dicer-null mice (10) and several angiomiRs have been identified $(9-11,13)$, there is limited information regarding their role in pancreatic carcinoma. Therefore, the present study aimed to identify angiomiRs in pancreatic CECs. Fourteen miRNAs were differentially expressed by $>20$-fold in the CECs of all three patients analyzed. Subsequent inhibition studies revealed that miR-139 and miR-200c may regulate CEC migration and tube formation but not proliferation.

In laryngeal squamous cell carcinoma, miR-139 expression decreased with disease progression, and in vitro and in vivo studies suggest that it inhibits proliferation, migration and metastasis (33). Similar tumor-suppressive functions have been reported in glioblastomas, hepatocellular carcinomas and gliomas (34-36). In contrast, miR-139 expression was upregulated in CECs as compared to NECs in the present study, which may be due to cell type-specific differences. 

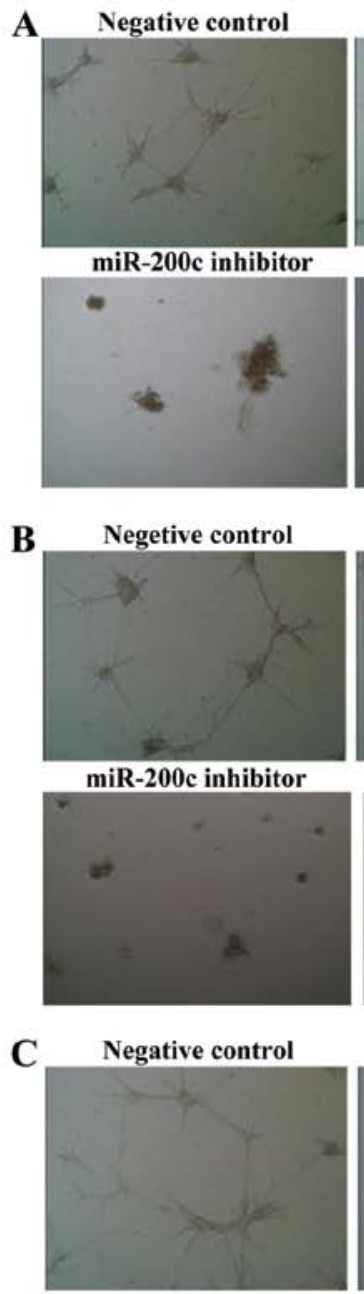

miR-200c inhibitor

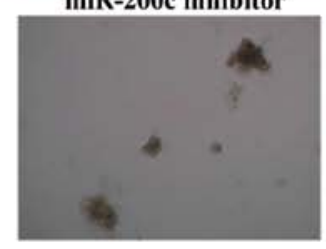

miR-1 inhibitor

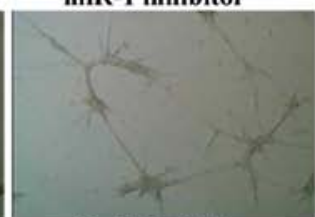

miR-193 inhibitor

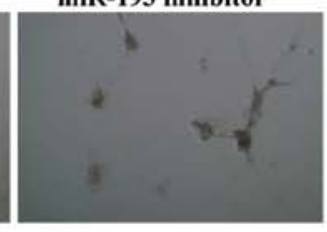

miR-1 inhibitor

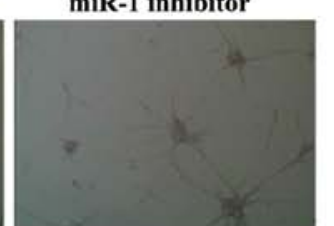

miR-193 inhibitor

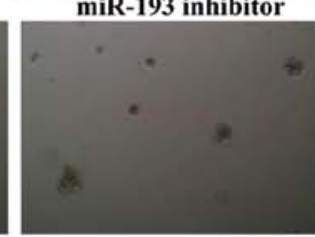

miR-1 inhibitor

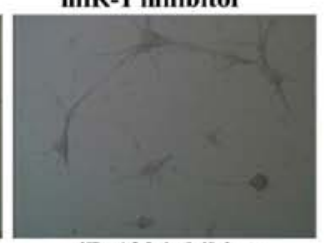

miR-193 inhibitor

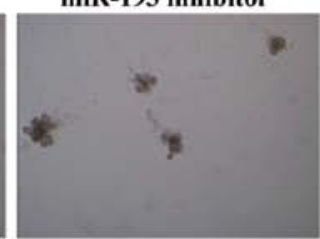

D
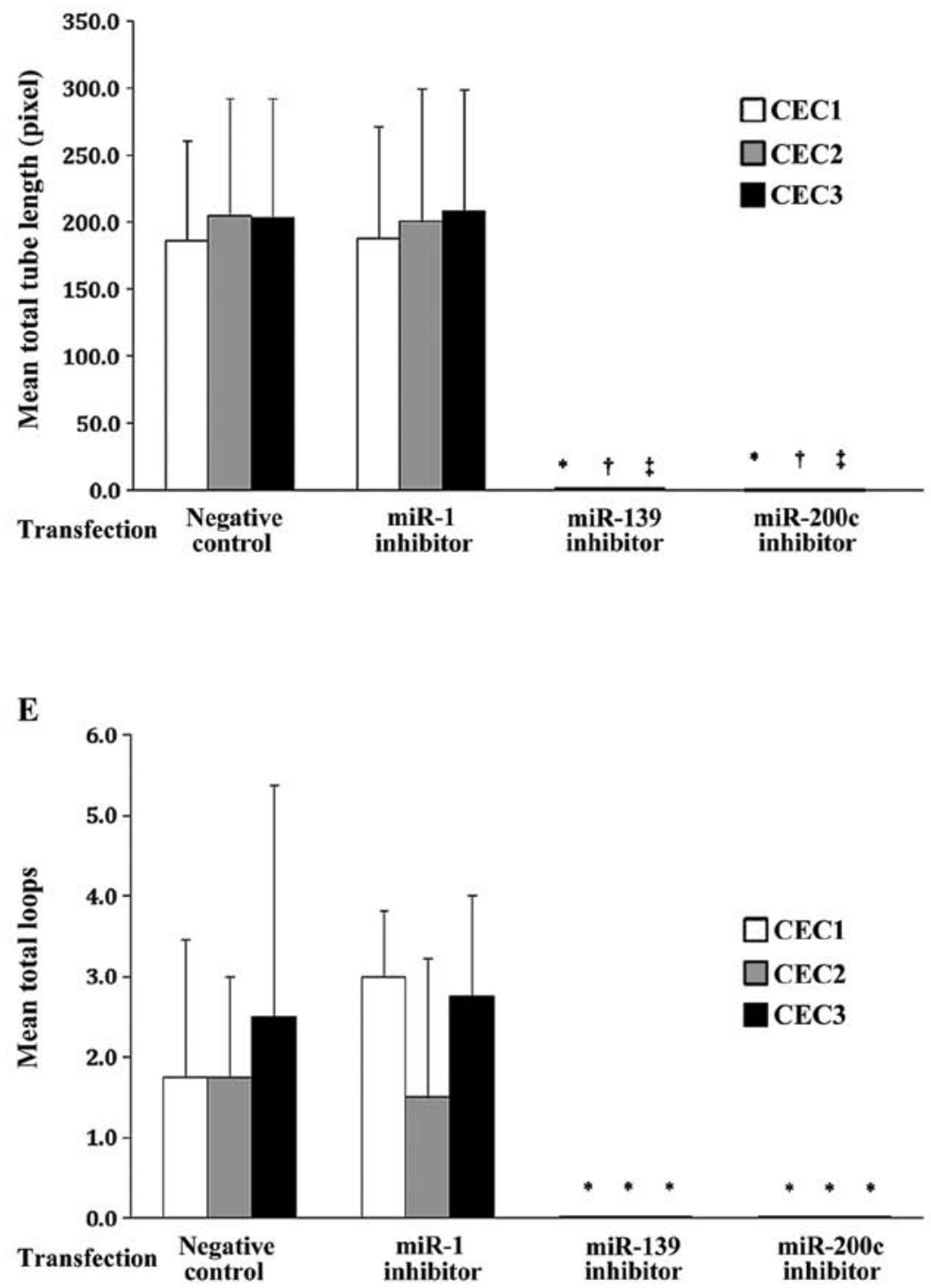

Figure 5. miR-139 and miR-200c regulate cancer endothelial cell (CEC) tube formation. Representative images from (A) CEC1, (B) CEC2 and (C) CEC3 are shown after transfection with the vector control or the miR-1, miR-200c or miR-193 inhibitors. (D) Mean tube length and (E) total loop number formation in the indicated groups. Data are presented as mean \pm SD for each condition (total of four randomly selected fields were calculated). The tube length and total loop number in cells treated with miR-139 and miR-200c inhibitors were set as 1 . One-sample t-tests were performed to evaluate the mean tube length or total loops, and differences between negative control and miR-1 inhibitor were compared using two-sample t-test. ${ }^{*+1} \mathrm{P}<0.05$, indicates a significant difference as compared with the negative control in ${ }^{*} \mathrm{CEC} 1,{ }^{+} \mathrm{CEC} 2$ and ${ }^{*} \mathrm{CEC} 3$. CEC1-3, cancer endothelial cells from patients 1-3.

In human embryonic stem cells, miR-200c was necessary for EC differentiation and in vivo vasculogenesis through inhibition of the transcription repressor, zinc finger E-boxbinding homeobox (ZEB1) (37). Reduced expression of miR-200c in leiomyomas, which are benign, fibrotic uterine tumors, altered ZEB1/ZEB2, VEFGA, FBLN5 and TIMP2 expression (38). In contrast, miR-200c expression is increased in endometrial cancer (39), and ectopic expression increased Ishikawa cell proliferation (40). Although we also observed increased miR-200c expression in the CECs as compared to NECs, its inhibition did not influence cell proliferation. However, inhibition of miR-200c reduced CEC migration and tube formation, which is similar to that reported for miR200a (15). Given the role of the putative miR-200c target genes in EMT, angiogenesis and matrix remodeling, further studies will evaluate the effects of miR-200c on tumor growth and metastasis.

Fourteen miRNAs were differentially expressed in the CECs of all three patients analyzed, among which the roles for miR-182, miR-183, miR-192, miR-194, the miR-200 family, miR-203, miR-27a*, miR-375 and miR-92a-1* in regulating tumor angiogenesis have been reported (16,22-32). Subsequent qPCR analysis of miR-200b, miR-182, miR-139 and miR-200c confirmed that miR-139 and miR-200c levels were increased in the CECs relative to the NECs. Such differences between the microarray results and qPCR validation may be attributed to the distance between the PCR primers and microarray probes for a specific gene (41) as well as spot intensity (42) 
and microarray data filtering (i.e., p-value) (43). Although both miR139 and miR-200c were selected for further analysis on the basis of their high expression and validation by qPCR, further studies will analyze the roles of the other miRNAs in angiogenesis.

In zebrafish embryos, inhibition of miR-1 inhibited angiogenesis and reduced EC levels (44). It also regulates cardiomyocyte progenitor cells (20). Although knockdown of miR-1 influenced CEC migration in the present study, no effects were observed on tube length and loop numbers. These differential effects may be due to tissue-specific regulation by miR-1.

The present study is limited in that the mechanism by which miR-139 and miR-200c influence cell migration and tube formation were not explored. Previous studies have reported that miR-139 targets chemokine receptor 4 (CXCR4) (33) and miR200c targets ZEBs, which regulate EMT during cancer development by repressing E-cadherin $(45,46)$, as well as VEGFA, FLT1, IKK $\beta$, KLF9, FBLN5 and TIMP2 $(38,40)$. Therefore, these putative miRNA targets will be explored further. In addition, the expression of CEC miRNAs was analyzed in only three pancreatic cancer patients; therefore, larger studies are necessary to determine the full significance of altered miRNA expression in pancreatic CECs. Furthermore, the differential miRNA expression observed in the present study may only be applicable for Asian patients as differential expression of miR-200c was noted in the leiomyomas of African-Americans vs. Caucasians (38). Finally, the effects of miR-139 and miR-200c on the proliferation, migration and vasculogenesis of NECs also need to be determined to fully explore the therapeutic potential of these miRNAs.

In summary, the present study identifies two miRNAs, miR-139 and miR-200c, that were upregulated in CECs derived from pancreatic tumors and that regulate CEC migration and tube formation. The therapeutic value of targeting these miRNAs in pancreatic cancer will be assessed in further in vivo studies.

\section{Acknowledgements}

We are deeply grateful to all the participants as well as to the doctors assisting with this study. This study was supported by the National Nature Science Foundation of China (81072006).

\section{References}

1. Maitra A and Hruban RH: Pancreatic cancer. Annu Rev Pathol 3: 157-188, 2008

2. Niederhuber JE, Brennan MF and Menck HR: The National Cancer Data Base report on pancreatic cancer. Cancer 76: 1671-1677, 1995.

3. Chen Y, Sun XJ, Jiang TH and Mao AW: Combined radiochemotherapy in patients with locally advanced pancreatic cancer: a meta-analysis. World J Gastroenterol 19: 7461-7471, 2013.

4. Folkman MJ, Long DM Jr and Becker FF: Growth and metastasis of tumor in organ culture. Cancer 16: 453-467, 1963.

5. Holmgren L, O'Reilly MS and Folkman J: Dormancy of micrometastases: balanced proliferation and apoptosis in the presence of angiogenesis suppression. Nat Med 1: 149-153, 1995.

6. Parangi S, O'Reilly M, Christofori G, Holmgren L, Grosfeld J, Folkman J and Hanahan D: Antiangiogenic therapy of transgenic mice impairs de novo tumor growth. Proc Natl Acad Sci USA 93: 2002-2007, 1996.

7. Folkman J: Tumor angiogenesis: therapeutic implications. N Engl J Med 285: 1182-1186, 1971.
8. Djuranovic S, Nahvi A and Green R: A parsimonious model for gene regulation by miRNAs. Science 331: 550-553, 2011.

9. Otsuka M, Zheng M, Hayashi M, Lee JD, Yoshino O, Lin S and Han J: Impaired microRNA processing causes corpus luteum insufficiency and infertility in mice. J Clin Invest 118: 1944-1954, 2008.

10. Yang WJ, Yang DD, Na S, Sandusky GE, Zhang Q and Zhao G: Dicer is required for embryonic angiogenesis during mouse development. J Biol Chem 280: 9330-9335, 2005.

11. Kuehbacher A, Urbich C, Zeiher AM and Dimmeler S: Role of Dicer and Drosha for endothelial microRNA expression and angiogenesis. Circ Res 101: 59-68, 2007.

12. Wang S and Olson EN: AngiomiRs - key regulators of angiogenesis. Curr Opin Genet Dev 19: 205-211, 2009.

13. Würdinger T, Tannous BA, Saydam O, Skog J, Grau S, Soutschek J, Weissleder R, Breakefield XO and Krichevsky AM: miR-296 regulates growth factor receptor overexpression in angiogenic endothelial cells. Cancer Cell 14: 382-393, 2008.

14. Zheng Y, Li S, Ding Y, Wang Q, Luo H, Shi Q, Hao Z, Xiao G and Tong S: The role of miR-18a in gastric cancer angiogenesis. Hepatogastroenterology 60: 1809-1813, 2013.

15. Poliseno L, Tuccoli A, Mariani L, Evangelista M, Citti L, Woods K, Mercatanti A, Hammond S and Rainaldi G: MicroRNAs modulate the angiogenic properties of HUVECs. Blood 108: 3068-3071, 2006.

16. Li YX, Liu DQ, Zheng C, Zheng SQ, Liu M, Li X and Tang H: miR-200a modulate HUVEC viability and migration. IUBMB Life 63: 553-559, 2011.

17. Raimondi L, Amodio N, Di Martino MT, Altomare E, Leotta M, CaraccioloD, Gullà A, Neri A, Taverna S, D'Aquila P, et al: Targeting of multiple myeloma-related angiogenesis by miR-199a-5p mimics: In vitro and in vivo anti-tumor activity. Oncotarget 5: 3039-3054, 2014.

18. Chamorro-Jorganes A, Araldi E, Rotllan N, Cirera-Salinas D and Suárez Y: Autoregulation of glypican-1 by intronic microRNA-149 fine tunes the angiogenic response to FGF2 in human endothelial cells. J Cell Sci 127: 1169-1178, 2014.

19. Naschberger E, Schellerer VS, Rau TT, Croner RS and Stürzl M: Isolation of endothelial cells from human tumors. Methods Mol Biol 731: 209-218, 2011.

20. van Mil A, Vrijsen KR, Goumans MJ, Metz CH, Doevendans PA and Sluijter JP: MicroRNA-1 enhances the angiogenic differentiation of human cardiomyocyte progenitor cells. J Mol Med 91: 1001-1012, 2013.

21. Chim SM, Qin A, Tickner J, Pavlos N, Davey T, Wang H, Guo Y, Zheng MH and Xu J: EGFL6 promotes endothelial cell migration and angiogenesis through the activation of extracellular signalregulated kinase. J Biol Chem 286: 22035-22046, 2011.

22. Amodeo V, Bazan V, Fanale D, Insalaco L, Caruso S, Cicero G, Bronte G, Rolfo C, Santini D and Russo A: Effects of antimiR-182 on TSP-1 expression in human colon cancer cells: there is a sense in antisense? Expert Opin Ther Targets 17: 1249-1261, 2013.

23. Donnem T, Fenton CG, Lonvik K, Berg T, Eklo K, Andersen S, Stenvold H, Al-Shibli K, Al-Saad S, Bremnes RM, et al: MicroRNA signatures in tumor tissue related to angiogenesis in non-small cell lung cancer. PLoS One 7: e29671, 2012.

24. Geng L, Chaudhuri A, Talmon G, Wisecarver JL, Are C, Brattain M and Wang J: MicroRNA-192 suppresses liver metastasis of colon cancer. Oncogene 33: 5332-5340, 2014.

25. Sundaram P, Hultine S, Smith LM, Dews M, Fox JL, Biyashev D, Schelter JM,Huang Q, Cleary MA, Volpert OV, et al: p53-responsive miR-194 inhibits thrombospondin-1 and promotes angiogenesis in colon cancers. Cancer Res 71: 7490-7501, 2011.

26. Pecot CV, Rupaimoole R, Yang D, Akbani R, Ivan $C, L u C, W u S$, Han HD, Shah MY, Rodriguez-Aguayo C, et al: Tumour angiogenesis regulation by the miR-200 family. Nat Commun 4: 2427, 2013.

27. Zhu X, Er K, Mao C, Yan Q, Xu H, Zhang Y, Zhu J, Cui F, Zhao W and Shi H: miR-203 suppresses tumor growth and angiogenesis by targeting VEGFA in cervical cancer. Cell Physiol Biochem 32: 64-73, 2013.

28. Tang W, Yu F, Yao H, Cui X, Jiao Y, Lin L, Chen J, Yin D, Song E and Liu Q: miR-27a regulates endothelial differentiation of breast cancer stem like cells. Oncogene 33: 2629-2638, 2014.

29. Urbich C, Kaluza D, Frömel T, Knau A, Bennewitz K, Boon RA, Bonauer A, Doebele C, Boeckel JN, Hergenreider E, et al: MicroRNA-27a/b controls endothelial cell repulsion and angiogenesis by targeting semaphorin 6A. Blood 119: 1607-1616, 2012. 
30. Reddi HV, Driscoll CB, Madde P, Milosevic D, Hurley RM, McDonough SJ, Hallanger-Johnson J, McIver B and Eberhardt NL: Redifferentiation and induction of tumor suppressors miR-122 and miR-375 by the PAX8/PPAR $\gamma$ fusion protein inhibits anaplastic thyroid cancer: a novel therapeutic strategy. Cancer Gene Ther 20 : $267-275,2013$

31. Ando H, Okamoto A, Yokota M, Shimizu K, Asai T, Dewa T and Oku N: Development of a miR-92a delivery system for antiangiogenesis-based cancer therapy. J Gene Med 15: 20-27, 2013.

32. Mendell JT: miRiad roles for the miR-17-92 cluster in development and disease. Cell 133: 217-222, 2008.

33. Luo HN, Wang ZH, Sheng Y, Zhang Q, Yan J, Hou J, Zhu K, Cheng Y, Xu YL, Zhang XH, et al: miR-139 targets CXCR4 and inhibits the proliferation and metastasis of laryngeal squamous carcinoma cells. Med Oncol 31: 789, 2014.

34. Skalsky RL and Cullen BR: Reduced expression of brain-enriched microRNAs in glioblastomas permits targeted regulation of a cell death gene. PLoS One 6: e24248, 2011.

35. Wong CC, Wong CM, Tung EK, Au SL, Lee JM, Poon RT, Man K and Ng IO: The microRNA miR-139 suppresses metastasis and progression of hepatocellular carcinoma by down-regulating Rho-kinase 2. Gastroenterology 140: 322-331, 2011.

36. Li RY, Chen LC, Zhang HY, Du WZ, Feng Y, Wang HB, Wen JQ, Liu X, Li XF, Sun Y, et al: MiR-139 inhibits Mcl-1 expression and potentiates TMZ-induced apoptosis in glioma. CNS Neurosci Ther 19: 477-483, 2013.

37. Luo Z, Wen G, Wang G, Pu X, Ye S, Xu Q, Wang W and Xiao Q: MicroRNA-200C and -150 play an important role in endothelial cell differentiation and vasculogenesis by targeting transcription repressor ZEB1. Stem Cells 31: 1749-1762, 2013.

38. Chuang TD, Panda H, Luo X and Chegini N: miR-200c is aberrantly expressed in leiomyomas in an ethnic-dependent manner and targets ZEBs, VEGFA, TIMP2, and FBLN5. Endocr Relat Cancer 19: 541-556, 2012.
39. Snowdon J, Zhang X, Childs T, Tron VA and Feilotter H: The microRNA-200 family is upregulated in endometrial carcinoma. PLoS One 6: e22828, 2011.

40. Panda H, Pelakh L, Chuang TD, Luo X, Bukulmez O and Chegini N: Endometrial miR-200c is altered during transformation into cancerous states and targets the expression of ZEBs, VEGFA, FLT1, IKK $\beta, K L F 9$, and FBLN5. Reprod Sci 19: 786-796, 2012.

41. Etienne W, Meyer MH, Peppers J and Meyer RA Jr: Comparison of mRNA gene expression by RT-PCR and DNA microarray. Biotechniques 36: 618-626, 2004.

42. Beckman KB, Lee KY, Golden T and Melov S: Gene expression profiling in mitochondrial disease: assessment of microarray accuracy by high-throughput Q-PCR. Mitochondrion 4: 453-470, 2004.

43. Morey JS, Ryan JC and Van Dolah FM: Microarray validation: factors influencing correlation between oligonucleotide microarrays and real-time PCR. Biol Proced Online 8: 175-193, 2006.

44. Lin CY, Lee HC, Fu CY, Ding YY, Chen JS, Lee MH, Huang WJ and Tsai HJ: miR-1 and miR-206 target different genes to have opposing roles during angiogenesis in zebrafish embryos. Nat Commun 4: 2829, 2013.

45. Davalos V and Esteller M: Opening the treasure chest of miR-200s family members. Cell Cycle 8: 2141-2142, 2009.

46. Brabletz S and Brabletz T: The ZEB/miR-200 feedback loop a motor of cellular plasticity in development and cancer? EMBO Rep 11: 670-677, 2010. 